\title{
Post-Arthroscopy Osteonecrosis of the Knee: With Special Reference to Meniscal Extrusion before and after the Medial Meniscectomy
}

\section{Jun Yamaguchi}

Jikei University School of Medicine: Tokyo Jikeikai lka Daigaku https://orcid.org/0000-0002-09367357

Kazunori Yasuda ( $\square$ yasukaz@med.hokudai.ac.jp)

https://orcid.org/0000-0002-0122-5928

\section{Eiji Kondo}

Hokkaido University Hospital

\section{Daisuke Ueda}

Yagi Orthopaedic Hospital

\section{Koji Yabuuchi}

Yagi Orthopaedic Hospital

\section{Jun Onodera}

Yagi Orthopaedic Hospital

\section{Norimasa Iwasaki}

Hokkaido University Graduate School of Medicine

\section{Mitsuru Saito}

Jikei University School of Medicine: Tokyo Jikeikai Ika Daigaku

\section{Tomonori Yagi}

Yagi Orthopaedic Hospital

\section{Research article}

Keywords: Osteonecrosis of the Knee, Arthroscopic meniscectomy, Meniscal extrusion, Meniscal location, Medial meniscus, Posterior root tear, Radial tear.

Posted Date: February 10th, 2021

DOI: https://doi.org/10.21203/rs.3.rs-200425/v1

License: (c) (1) This work is licensed under a Creative Commons Attribution 4.0 International License.

Read Full License 


\section{Abstract}

Background: Post-arthroscopic osteonecrosis of the knee (PAONK) is a rare disorder

condition. In addition, no studies have analyzed the relationship between the meniscus extrusion and PAONK. The purposes of this retrospective study are to report 10 cases of PAONK and to evaluate location of the MM in the joint space, including the meniscus

9 extrusion, before and after the meniscectomy in these 10 knees.

Methods: Ten knees with PAONK were found in 876 knees which had undergone

11 arthroscopic partial meniscectomy of the medial meniscus (MM). We retrospectively collected the clinical, surgical, and radiological data of these 10 patients. To evaluate intraarticular location of the menisci in the joint space, Extrusion width and Inner width were defined on magnetic resonance images, and they were statistically compared.

Results: In the 10 patients ( 2 men and 8 women; the age ranged between 60 and 80 years), knee pain recurred within 12 weeks after the meniscectomy. Preoperatively, the Extrusion width of the MM (the mean, $4.7 \mathrm{~mm})$ was significantly greater $(\mathrm{P}<0.0001)$ than that of the LM $(0.2 \mathrm{~mm})$. At the time of diagnosis of PAONK, the Extrusion width of the MM 
19 significantly increased by $1.2 \mathrm{~mm}$ and the Inner width was significantly reduced by 3.9

$20 \mathrm{~mm}$, compared with the preoperative values $(\mathrm{P}<0.0001)$.

21 Conclusion: This is the first report that, in each of the 10 knees with PAONK, the MM

22 had been extruded before the meniscectomy, and then, the Inner width of the MM almost

23 disappeared postoperatively due to not only the increased meniscal extrusion but the

24 partial meniscal resection. This study suggested that the intraarticular abnormal location

25 of the MM, including the meniscal extrusion, is a critical factor that should be evaluated

26 in future studies to clarify causative factors of PAONK.

27

28 Keywords: Osteonecrosis of the Knee, Arthroscopic meniscectomy, Meniscal extrusion,

29 Meniscal location, Medial meniscus, Posterior root tear, Radial tear.

30

31 


\section{Background}

Osteonecrosis of the knee was reported by Ahlbäck et al. [1] in 1968. Currently, it has been classified into 3 categories, spontaneous osteonecrosis (SPONK), secondary osteonecrosis, and post-arthroscopic osteonecrosis of the knee (PAONK). [8] Concerning PAONK, Brahme et al. [5] described the first report entitled "osteonecrosis of the knee after arthroscopic surgery" in 1991. Later, similar pathological conditions were reported as "postmeniscectomy osteonecrosis" [9, 23, 24]. In 2007, Pape et al. [22] reviewed 47 previously reported cases of these pathological conditions, and they named them "PAONK". Thus, PAONK is defined as a type of knee osteonecrosis that occurs in patients who underwent arthroscopic knee surgery. Clinical diagnosis of PAONK is made with magnetic resonance imaging (MRI), while findings on the MRI are the same as those for SPONK. [8] An important criterion in diagnosing PAONK is to confirm that any signs of osteonecrosis were not observed in the MRI taken prior to the meniscectomy. [8]

PAONK is a rare disorder condition so that the incidence has been reported to be $0.2-1.5 \%$ of the knees which underwent arthroscopic surgery. [23, 24] Therefore, the etiology of PAONK has not been fully clarified. To clarify the etiology, it is needed to increase the patient database on PAONK. For example, previous studies concerning PAONK have not focused on the meniscus location in the joint space before and after 
arthroscopic surgery. Particularly, no studies have analyzed the relationship between the meniscus extrusion and PAONK. Recently, Oda et al. [21] reported that there was a significant correlation between the meniscal extrusion and the SPONK. Therefore, it is required to analyze a relationship between the meniscal extrusion and the PAONK. In our clinical practice, we found 10 knees with PAONK in 876 knees which had undergone arthroscopic partial meniscectomy of the medial meniscus (MM). The first purpose of the present study is to report the clinical status of the 10 patients in detail to increase the database of PAONK. The second purpose is to clarify whether these 10 knees had abnormal location of the MM in the joint space, including the meniscus extrusion, before and after the arthroscopic partial meniscectomy.

60

Methods

62 1) Diagnosis of PAONK PAONK was diagnosed with MRI examinations using the following criteria (Johnson 2000, Di Caprio 2017) [8, 12] : (1) The patient complained of serious pain in the knee which had undergone arthroscopic surgery within the past 12 months. (2) The MRI showed osteonecrosis in the femoral condyle or the tibial plateau at the ipsilateral side of the arthroscopic surgery. (3) Retrospectively, the MRI taken immediately before the 
arthroscopic surgery did not show any evidence of bone marrow edema (BME) or osteonecrosis. Then, the diagnosis of osteonecrosis was made, based on the following

70 findings in the T1- and T2*-weighted MRI. $[4,17,18]$ (1) In the early stages, a necrotic

71 lesion was observed in the femoral condyle or tibial plateau as a low signal area

72 surrounded by an extensive BME area. (2) At the margin of the necrotic lesion, a high signal line was often observed, delineating the necrotic area from the adjacent area of

74 BME. Commonly, the BME is gradually reduced by approximately 3 months. (3) In the late stage, bone sequestration or segmentation was sometimes observed with a surrounding high signal rim in the flattened femoral condylar.

\section{2) Patients}

In our hospital (\#\#\#\# \#\#\#\#\#\#\# Hospital, \#\#\#\#, \#\#\#), arthroscopic partial meniscectomy was performed in 876 knees between 2010 and 2015. In following up these patients postoperatively for 1 year in our outpatient clinic, we found 10 cases $(2$ men and 8 women) of PAONK. Concerning these 10 patients, we retrospectively collected the

83 clinical, surgical, and radiological data and added statistical analyses. The study design was accepted by the Ethical Review Board in our hospital. 
87 The radiological stage of osteoarthritis (OA) was evaluated using the Kellgren and

88 Lawrence (KL) grades [13]. The radiological stage of osteonecrosis of the knee was

89 evaluated using Koshino's classification [14] (Table 2). In the present study, the MRI was

90 taken with 0.2-T MRI (Aris; Hitachi, Tokyo, Japan). For T1-weighted images, the

91 protocol included both sagittal and coronal spin-echo sections with TR/TE values of 550

92 per 27 milliseconds. For T2*-weighted images, we used gradient-echo sections with

93 TR/TE of 660 per 17 milliseconds (FA of 30 degrees). Section thickness was between 4

94 and $5 \mathrm{~mm}$ with 4-mm intervals. An extremity coil was used with a field of view of 150

$95 \mathrm{~mm}, 256 \times 256$ matrix.

The location of the MM in the joint space, including the degree of extrusion of

97 the MM, was quantified using the following method, which was created by modification

98 of Costa's method [7]. On the coronal image of the MRI at the midpoint of the medial

99 femoral condyle, a vertical line intersecting the peripheral margin of the medial tibial

100 plateau was drawn (Figure 1). Osteophytes were excluded in determining the medial

101 margin. Then, the second and third lines, which were parallel to the first line, were drawn

102 at the outer (peri-articular) and inner (intra-articular) margins of the meniscus,

respectively (Figure 1). We measured the distance between the first and second lines, 
104 which was defined as "Extrusion width", and the distance between the first and third lines,

105 which was defined as "Inner width" (Figure 1). Each width was quantified in millimeters.

106 This method was applied to the lateral joint space in the same manner to quantify the

107 location of the lateral meniscus (LM). Locations of the MM and LM in the joint space

108 was measured before the arthroscopic surgery and at the time when the diagnosis of

109 PAONK was made.

110

111 4) Statistics

112 Statistical comparisons were made using the paired or unpaired t-test. The significance

113 level was set at $\mathrm{P}<0.05$.

114

$115 \quad$ Results

116 1) Characteristics of the patients before meniscectomy

117 Patients characteristics before meniscectomy are shown in Table 1 . The age of the 10

118 patients ( 2 men and 8 women) at the time of the arthroscopic meniscectomy ranged

119 between 60 and 80 years (average 67.5 years). The body mass index averaged $25.9 \%$. In

120 arthroscopic observation, not only MM injury but also chondromalacia on MFC were

121 found in all the 10 knees. In addition, chondromalacia on the medial tibial plateau (MTP) 
was observed in 8 knees. Two knees showed grade-1 OA and 7 knees showed grade-2

123 OA, while the remaining one knee showed no osteoarthritic changes. The preoperative

124 femorotibial angle (FTA) ranged between 168 and 182 degrees (average 176 degrees).

2) Characteristics of the performed meniscectomy

127 Characteristics of the performed meniscectomy are shown in Table 2. In the 10 knees, 5

128 knees had a posterior root tear of the MM, and the other 5 knees had a radial tear at the posterior horn of the MM. Three radial tears and 2 posterior root tears involved horizontal

130 tears at the posterior horn. For these MM tears, arthroscopic partial meniscectomy at the 131 torn portion was performed. The LM simultaneously underwent trimming at the limited

132 lesion in 2 of the 10 knees and meniscal repair in 1 knee. Total width of the MM was resected around the torn site in 8 knees, while approximately half width of the MM was

134 resected in 2 knees. The time needed for surgery ranged between 25 and 55 minutes (the average of 34.5 minutes). Intraoperatively, an air tourniquet was used in 7 knees, while it was not used in the remaining 3 knees.

\section{3) Characteristics in the post-operative course}

139 Characteristics in the post-operative course are shown in Table 3. After arthroscopic 
140 meniscectomy, 9 of the 10 patients returned to their usual daily activities, although 3 of

141 the 9 patients felt some mild pain in the ipsilateral knee while walking. In these 9 patients,

142 serious knee pain recurred 3 to 12 weeks (the mean, 5.7 weeks) after the meniscectomy

143 so that each patient visited the outpatient clinic of our hospital. The remaining one patient

144 continuously felt moderate knee pain after the meniscectomy. The 10 patients underwent

145 an MRI examination 3 to 21 weeks (the mean, 12.0 weeks) after the meniscectomy. The

146 MRI showed that an osteonecrosis lesion with BME was found at the MFC in 8 knees

147 and at both the MFC and the MTP in 2 knees. The osteonecrosis lesions were classified

148 as Stage 1 in 4 knees, Stage 2 in 4 knees, and Stage 3 in 2 knees, according to Koshino's

149 classification. The KL grade of knee osteoarthritis was advanced by 1 grade in 3 knees

150 and by 2 grades in 1 knee, when compared with the grade evaluated before the

151 meniscectomy, while 6 knees showed no changes in the KL grade. The FTA showed no

152 significant difference compared with the pre-operative FTA.

\section{4) Intraarticular location of the menisci}

155 Before the arthroscopic meniscectomy, the MRI showed that the intraarticular location of

156 the MM was abnormal in each of the 10 patients, while that of the LM was normal (Table

4). In the measurements, the Extrusion width of the MM averaged $4.7 \mathrm{~mm}$ with a range 
between 2.8 and $6.8 \mathrm{~mm}$, which was significantly greater $(\mathrm{P}<0.0001)$ than that of the LM

159 (the mean, $-0.2 \mathrm{~mm}$ ). The Inner width of the MM averaged $4.4 \mathrm{~mm}$ with a wide range 160 between 0.0 and $7.1 \mathrm{~mm}$, which was significantly less $(\mathrm{P}<0.0001)$ than that of the $\mathrm{LM}$ (the 161 mean, $9.1 \mathrm{~mm}$ ). The MRI, which was taken at the time of diagnosis of PAONK, showed 162 that the degree of the Extrusion of the MM increased and the Inner width decreased in all the patients. In the measurements (Table 4), the Extrusion width of the MM averaged 5.9

$164 \mathrm{~mm}$, which was significantly greater $(\mathrm{P}<0.0001)$ than that of the $\mathrm{LM}$ (the mean, $-0.2 \mathrm{~mm})$, 165 and it was slightly but significantly increased by $1.2 \mathrm{~mm}(\mathrm{P}<0.0001)$ in comparison with 166 the width measured before the meniscectomy (Figure 4). The Inner width of the MM 167 averaged $0.6 \mathrm{~mm}$, which was significantly less $(\mathrm{P}<0.0001)$ than that of the $\mathrm{LM}$ (the mean, $1688.9 \mathrm{~mm})$, and it was significantly reduced by $3.9 \mathrm{~mm}(\mathrm{P}<0.0001)$ in comparison with the 169 width measured before the meniscectomy (Figure 4).

\section{5) Representative cases}

172 Case 1: 62-year old woman (Patient No. 6 in Tables). She had suffered from pain in the

173 left knee during walking for 3 months, before she visited our outpatient clinic. The radiograms showed grade-1 OA (Figure 2-A). The MRI examination showed a posterior root tear of the MM with degenerative changes in the posterior horn, while it did not show 
176 any findings of osteonecrosis or BME (Figure 2-B, C, D). The Inner width and the

177 Extrusion width of the MM were $6.1 \mathrm{~mm}$ and $3.5 \mathrm{~mm}$, respectively. Conservative therapy

178 was not effective so that she underwent arthroscopic partial meniscectomy of the

179 degenerated portion. Postoperatively, she returned to unrestricted daily life activity within

180 one month. Then, she felt severe pain in the ipsilateral knee while walking 2 months after

181 the meniscectomy, and she visited our outpatient clinic 3 months postoperatively. The

182 radiograms indicated stage-3 osteonecrosis in the medial femoral condyle (MFC), in

183 which a radiolucent lesion with a calcified plate was observed (Figure 2-E). MRI showed

184 a necrotic lesion (T1-low, T2*-high) in the MFC, which was surrounded by an

185 osteosclerotic zone and a wide BME area (Figure 2-F, G, H). The Inner width of the MM

186 decreased to $1.4 \mathrm{~mm}$, and the Extrusion width slightly increased to $6.1 \mathrm{~mm}$. The severe

187 knee pain continued in spite of conservative treatment so that unilateral knee arthroplasty

188 was performed.

189 Case 2: 64-year old man (Patient number 2 in Tables). He had suffered from pain

190 in the right knee while walking for a period of 2 months, before he visited our outpatient

191 clinic. The radiograms indicated grade-2 OA (Figure 3-A). The MRI examination showed

192 a degenerative radial tear at the posterior horn of the MM, while it did not show any

193 findings of osteonecrosis or BME (Figure 3-B, C, D). The Inner width and the Extrusion 
194 width of the MM were $6.9 \mathrm{~mm}$ and $4.1 \mathrm{~mm}$, respectively. Conservative therapy was not

195 effective so that he underwent arthroscopic partial meniscectomy of the torn portion.

196 Postoperatively, he returned to unrestricted daily life activity within one month. Three

197 months after the meniscectomy, he felt severe pain in the ipsilateral knee while walking.

198 He revisited our outpatient clinic 4 months after the meniscectomy. The radiograms

199 indicated stage-2 osteonecrosis in the MFC, in which we could observe a bone-absorbed

200 lesion surrounded by an osteosclerotic zone (Figure 3-E). MRI showed a necrotic lesion

201 (T1-low, T2*-high) in the MFC, which was surrounded by an osteosclerotic zone (Figure

$2023-\mathrm{F}, \mathrm{G}, \mathrm{H})$. The Inner width of the MM decreased to $1.2 \mathrm{~mm}$, and the Extrusion width

203 slightly increased to $4.2 \mathrm{~mm}$. Although conservative treatments were applied, the knee

204 pain gradually increased. Subsequently, high tibial osteotomy with autologous

205 osteochondral transplantation was performed 15 months after the meniscectomy.

\section{Discussion}

208 The first purpose of the present study was to report the clinical status of the 10 patients

209 in detail in order to increase the database of PAONK. Previous studies have pointed out

210 that orthopaedic surgeons should have sufficient knowledge on PAONK [8, 9, 22]. Pape et al. [22] reported the following clinical characteristics of PAONK in their review study: 
212 First, there was no difference in the incidence between men and women. Secondly, the

213 average age at the onset in their 47 cases was 58 years, which was younger compared

214 with that for SPONK. Thirdly, PAONK occurred after medial meniscectomy in $87 \%$ and

215 after lateral meniscectomy in 13\%. Fourthly, PAONK occurred at the MFC in $83 \%$ of the

216 cases, at the lateral femoral condyle in $8.5 \%$, at the MTP in $4.3 \%$, and at the lateral tibial

217 plateau in $4.3 \%$. Fifthly, articular cartilage injuries were found in $65 \%$ of the patients. In

218 the present study, the clinical characteristics of the 10 patients with PAONK almost agreed

219 with those reported by Pope except for the following points: (1) The age of our patients

220 (67.5 years in average) was higher by approximately 10 years in comparison with Pape's

221 report. (2) Cartilage injuries were observed before the meniscectomy in all patients. These

222 differences may reflect a fact that the aging rate in Japan, currently $27.3 \%$, is the highest

223 in the world. In the present study, $90 \%$ of the patients with PAONK felt severe pain within

2246 months after MM resection. Therefore, it is recommended that, when a patient who

225 returned to daily life after meniscectomy complains of acute knee pain during walking,

226 the orthopaedic surgeon should examine the patient with MRI to check for a potential

227 onset of PAONK.

The most important finding in the present study was obtained by achieving the 
230 been obviously extruded before and after the arthroscopic meniscectomy, and the degree

231 of the extrusion significantly increased at the period of diagnosis of PAONK. Furthermore,

232 the Inner width of the MM was extremely reduced at the time of diagnosis of PAONK.

233 Figure 4 shows two facts. First, in the 10 patients with PAONK, the Inner width of the

234 MM almost disappeared even though the meniscectomy was partial. This means a

235 complete loss of meniscal functions. Secondly, the disappearance of the Inner width of

236 the MM was caused by not only the decrease of the total meniscal width due to

237 meniscectomy but also the meniscal extrusion, which had existed before the

238 meniscectomy and then increased following it. No studies have reported the abnormal

239 location of the MM in the knees with PAONK. Therefore, the present study provided new

240 important information to the research field to clarify the etiology of PAONK. In addition,

241 the present study suggests that, when orthopaedic surgeons follow up a patient who

242 underwent arthroscopic partial meniscectomy of the extruded MM, the surgeons should

243 pay special attention to a high risk of PAONK.

Then, we considered the relationship between the abnormality on the intraarticular location of the MM and the onset of PAONK. In the 10 patients of the present study, it is noted that, first, the MM extrusion had existed prior to the arthroscopic meniscectomy. The meniscal extrusion is caused by root tear, radial tear, and degeneration 
248 of the meniscus $[6,7,25]$, resulting in an increase of the contact stress [16]. Secondly,

249 the Inner width of the MM almost disappeared at the time of diagnosis of the PAONK

250 due to not only the partial resection of the meniscus tissue but also the increase of the

251 meniscal extrusion. This meniscal status means that the normal meniscal function, which

252 is to reduce the joint contact stress, was almost completely lost $[2,15]$. It is known that

253 loss of the meniscal function results in an increase of the joint contact stress, leading to a

254 progression of knee osteoarthritis [3, 25]. Recently, Oda et al. [21] reported that there was

255 a significant correlation between the meniscal extrusion and the SPONK. Therefore, there

256 is a high possibility that, in the present study, the abnormal location of the MM in the

257 joint space might induce an insufficiency fracture of the subchondral bone of the femoral

258 condyle or the tibial plateau, resulting in PAONK. This possibility is supported by the

259 fact that the BME lesion, which commonly shows existence of insufficiency fracture, was

260 observed in each knee with PAONK However, the present study could not clarify whether

261 the decrease of the Inner width of the MM due to the meniscal extrusion and the partial

262 meniscal resection was one of the causes of PAONK, because we had no comparative

263 data. However, this study is of value because it suggested that the intraarticular abnormal

264 location of the MM, including the meniscal extrusion, is a critical factor that should be evaluated in future studies to clarify causative factors of PAONK. 
proposed [8]. However, recent studies have shown that an essential pathology of PAONK

268 is a subchondral bone fracture, and that the necrotic bone lesion is a secondary condition

269 of the fractured bone [10, 18, 20]. For example, Higuchi et al. [10] performed a

270 histological examination in 6 cases of PAONK. In the results, subchondral bone fracture

271 was observed in all 6 knees, but necrotic lesion was not detected at all in 4 of the 6 knees.

272 MacDessi et al. [18] carried out histological examination in 8 knees with PAONK. In their

273 results, subchondral bone fracture with a callus formation was observed in all the 8 knees,

274 but a necrotic bone tissue, which appeared to be a secondary lesion to the fracture, was

275 found in only two knees. Then, in the 10 knees of the present study, the MRI taken in the

276 early phase after recurrence of the knee pain showed that the BME lesion, which is

277 commonly seen around an insufficiency fracture lesion, was widely observed in the MFC

278 and/or the MTP. In the late phase after recurrence of the knee pain, a low intensity zone

279 in both the T1- and T2*-weighted images, which showed osteonecrosis, was observed at

280 only a localized area in the subchondral bone. These findings in the present study

281 supported the above-described histopathological studies. 
284 subchondral insufficiency fracture, and that the localized necrosis of the bone tissue seen

285 in association with SPONK is a secondary lesion following the fracture of the subchondral

286 bone tissue. It is noted that this pathology of SPONK is the same as the above-described

287 pathology of PAONK. Recently, Hussain et al. [11] conducted a pathological review study

288 and concluded that SPONK and PAONK have the same histopathology. In addition,

289 recent clinical studies reported that meniscal extrusion causes SPONK [21, 27]. The

290 present study also suggested that a decrease of the Inner width of the MM with an increase

291 of the meniscal extrusion might cause PAONK. These facts support the concept that

292 SPONK and PAONK have the same histopathological condition. Therefore, we consider

293 that, although PAONK has been classified as a different type of osteonecrosis from

294 SPONK in the clinical field, $[5,9,22]$ the classification of osteonecrosis of the knee

295 should be revised to precisely understand this pathological condition and to appropriately

296 treat it.

This is a report dealing with 10 rare cases of PAONK. Therefore, there are

298 limitations in the present study. First, the number of patients was insufficient. Secondly,

299 there were no control data to clarify the effect of the abnormal location of the MM on

300 occurrence of PAONK. However, we believe that this report will contribute to future

studies, because this is the first report that abnormal location of the MM, including 
meniscal extrusion, was observed in each of the 10 patients not only at the time of diagnosis of PAONK but before the prior meniscectomy.

\section{Conclusion}

306 Ten knees were diagnosed as PAONK in 876 knees which had undergone arthroscopic

307 partial meniscectomy of the MM. In the 10 patients, the MM had been extruded (the mean,

$3084.7 \mathrm{~mm}$ ) before the meniscectomy, and then, the Extrusion width significantly increased

$309(\mathrm{P}<0.0001)$ and the Inner width of the MM was significantly reduced $(\mathrm{P}<0.0001)$ at the

310 time of diagnosis of PAONK. This is the first report that, in each of the 10 knees with

311 PAONK, the MM had been extruded before the meniscectomy, and then, the Inner width

312 of the MM almost disappeared postoperatively due to not only the increased meniscal

313 extrusion but the partial meniscal resection. This study suggested that the intraarticular

314 abnormal location of the MM, including the meniscal extrusion, is a critical factor that

315 should be evaluated in future studies to clarify causative factors of PAONK.

\section{List of abbreviations}

BME: bone marrow edema, FTA: femorotibial angle, KL: Kellgren and Lawrence,

LM: lateral meniscus, MFC: medial femoral condyle, MM: medial meniscus, MRI: 
magnetic resonance imaging, MTP: medial tibial plateau, OA: osteoarthritis, PAONK: post-arthroscopic osteonecrosis of the knee, SPONK: spontaneous osteonecrosis.

\section{Declarations}

324 - Ethical approval and consent to participate

325 Ethical approval was given by the Ethical Review Board in Yagi Orthopaedic Hospital,

326 Sapporo, Japan. A written consent was obtained from all participants prior to this study.

327

328

$329 \quad$ Not applicable.

330 the corresponding author on reasonable request.

336 The authors declare that they have no competing interest. 
Hospital, Sapporo, Japan.

\section{- Author contributions}

344 designed this study and completed the draft. DU, KYabuuchi, and JO supported the data

346 draft critically. TY conducted this study and supervised the data analysis. All authors have read and approved the manuscript.

\section{References}

354 1. Ahlbäck S, Bauer GC, Bohne WH. Spontaneous osteonecrosis of the knee. 
2. Allaire R, Muriuki M, Gilbertson L, Harner CD. Biomechanical consequences of a tear of the posterior root of the medial meniscus: similar to total meniscectomy. J Bone Joint Surg Am. 2008;90:1922-31.

3. Berthiaume MJ, Raynauld JP, Martel PJ, Labonté F, Beaudoin G, Bloch D, et al. Meniscal tear and extrusion are strongly associated with progression of symptomatic knee osteoarthritis as assessed by quantitative magnetic resonance imaging. Ann Rheum Dis. 2005;64:556-63.

4. Bjorkengren AG, Al-Rowaih A, Lindstrand A, Wingstrand H, Thorngren KG, Pettersson H. Spontaneous osteonecrosis of the knee: Value of MR imaging in determining prognosis. AJR Am J Roentgenol. 1990;154:331-6.

5. Brahme SK, Fox JM, Ferkel RD, Friedman MJ, Flannigan BD, Resnick DL. Osteonecrosis of the knee after arthroscopic surgery: diagnosis with MR imaging. Radiology. 1991;178:851-3.

6. Costa CR, Morrison WB, Carrino JA. Medial meniscus extrusion on knee MRI: Is extent associated with severity of degeneration or type of tear?. AJR Am J Roentgenol. 2004;183:17-23.

7. Crema MD, Roemer FW, Felson DT, Englund M, Wang K, Jarraya M, et al. Factors Associated with Meniscal Extrusion in Knees with or at Risk for 

503.

8. Di Caprio F, Meringolo R, Navarra MA, Mosca M, Ponziani L. Postarthroscopy

378 9. Faletti C, Robba T, de Petro P. Postmeniscectomy osteonecrosis. Arthroscopy. 2002;18:91-4.

10. Higuchi H, Kobayashi Y, Kobayashi A, Hatayama K, Kimura M. Histologic analysis of postmeniscectomy osteonecrosis. Am J Orthop. 2013;42:220-2.

11. Hussain ZB, Chahla J, Mandelbaum BR, Gomoll AH, LaPrade RF. The Role of Meniscal Tears in Spontaneous Osteonecrosis of the Knee: A Systematic Review

12. Johnson TC, Evans JA, Gilley JA, DeLee JC. Osteonecrosis of the knee after of Suspected Etiology and a Call to Revisit Nomenclature. Am J Sports Med. Rheum Dis. 1957;16:494-502. 2019;47:501-7.

arthroscopic surgery for meniscal tears and chondral lesions. Arthroscopy. 2000;16:254-61.

13. Kellgren JH, Lawrence JS. Radiological assessment of osteo-arthrosis. Ann 14. Koshino T. The treatment of spontaneous osteonecrosis of the knee by high tibial 
osteotomy with and without bone-grafting or drilling of the lesion. J Bone Joint Surg Am. 1982;64:47-58.

15. Krause WR, Pope MH, Johnson RJ, Wilder DG. Mechanical changes in the knee after meniscectomy. J Bone Joint Surg Am. 1976;58:599-604.

16. Lerer DB, Umans HR, Hu MX, Jones MH. The role of meniscal root pathology

17. Lotke PA, Ecker ML. Current concepts review. Osteonecrosis of the knee. J Bone Joint Surg Am. 1988;70:470-3.

18. MacDessi SJ, Brophy RH, Bullough PG, Windsor RE, Sculco TP. Subchondral fracture following arthroscopic knee surgery. A series of eight cases. J Bone Joint Surg Am. 2008;90:1007-12.

19. Muscolo DL, Costa-Paz M, Makino A, Ayerza MA. Osteonecrosis of the knee following arthroscopic meniscectomy in patients over 50-years old. Arthroscopy. $1996 ; 12: 273-9$.

20. Nakamura N, Horibe S, Nakamura S, Mitsuoka T. Subchondral microfracture of the knee without osteonecrosis after arthroscopic medial meniscectomy. Arthroscopy. 2002;18:538-41. 
21. Oda S, Fujita A, Moriuchi H, Okamoto Y, Otsuki S, Neo M. Medial meniscal extrusion and spontaneous osteonecrosis of the knee. J Orthop Sci. 2019;24:86772.

22. Pape D, Seil R, Anagnostakos K, Kohn D. Postarthroscopic osteonecrosis of the knee. Arthroscopy. 2007;23:428-38.

23. Pruès-Latour V, Bonvin JC, Fritschy D. Nine cases of osteonecrosis in elderly patients following arthroscopic meniscectomy. Knee Surg Sports Traumatol Arthrosc. 1998; 6:142-7.

24. Santori N, Condello V, Adriani E, Mariani PP. Osteonecrosis after arthroscopic medial meniscectomy. Arthroscopy. 1995;11:220-4.

25. Swamy N, Wadhwa V, Bajaj G, Chhabra A, Pandey T. Medial meniscal extrusion: Detection, evaluation and clinical implications. Eur J Radiol. 2018;102:115-24.

26. Yamamoto T, Bullough PG. Spontaneous osteonecrosis of the knee: the result of subchondral insufficiency fracture. J Bone Joint Surg Am. 2000;82:858-66.

27. Yasuda T, Oda S, Fujita S, Onishi E, Iwaki K, Yamamoto H. Association between medial meniscus extrusion and spontaneous osteonecrosis of the knee. Int J Rheum Dis. 2018;21:2104-11. 


\section{Legends of Figures}

430 Fig. 1 Measurement of the location of the medial meniscus (MM) on the coronal image

431 of the MRI. A vertical line intersecting the peripheral margin of the medial tibial plateau

432 (MTP) was drawn. Then, the second and third lines, which were parallel to the first line,

433 were drawn at the outer and inner margins of the meniscus, respectively. We measured

434 the distance between the first and second lines, which was defined as "Extrusion width

435 (EW)", and the distance between the first and third lines, which was defined as "Inner

436 width (IW)". Each width was quantified in millimeters.

437

438 Fig. 2 62-year old woman. Preoperatively, the radiogram (A) showed grade-1 OA. The MR images (B and C: T2*, D: T1) did not show any findings of osteonecrosis or bone marrow edema (BME). The Inner width (IW) and the Extrusion width (EW) of the MM were $6.1 \mathrm{~mm}$ and $3.5 \mathrm{~mm}$, respectively (B). At 3 months postoperatively, the radiograms (E) indicated stage-3 osteonecrosis in the medial femoral condyle (MFC). MR images (F and G: T2*, H: T1) showed a necrotic lesion (T1-low, T2*-high) in the MFC, which was surrounded by an osteosclerotic zone and a wide BME area. The IW decreased to $1.4 \mathrm{~mm}$, and the EW increased to $6.1 \mathrm{~mm}(\mathrm{~F})$. 
447 Fig. 3 64-year old man. Preoperatively, the radiogram (A) showed grade-2 OA. The 448 MR images (B and C: T2*, D: T1) did not show any findings of osteonecrosis or bone 449 marrow edema (BME). The Inner width (IW) and the Extrusion width (EW) of the MM 450 were $6.9 \mathrm{~mm}$ and $4.1 \mathrm{~mm}$, respectively (B). At 4 months postoperatively, the radiograms 451 (E) indicated stage-2 osteonecrosis in the medial femoral condyle (MFC). MR images (F 452 and G: T2*, H: T1) showed a necrotic lesion (T1-low, T2*-high) in the MFC, which was 453 surrounded by an osteosclerotic zone. The IW decreased to $1.2 \mathrm{~mm}$, while the EW was $454 \quad 4.2 \mathrm{~mm}(\mathrm{~F})$.

Fig. 4 A: Comparison of the medial meniscus (MM) locations measured before the meniscectomy (Preop) and at the time of diagnosis of PAONK (@Diagnosis). The Extrusion width (EW) and the Inner width (IW), the definition of which is shown in a schematic picture $(\mathrm{B})$, were significantly $(\mathrm{P}<0.0001)$ changed between the 2 periods. This bar graph also shows that the disappearance of the IW of the MM was caused by not only the decrease of the total meniscal width due to meniscectomy but also the meniscal extrusion. 
Table 1 Characteristics of the 10 patients with PAONK concerning the preoperative factors. F: female, M: male, R: right, L: left, BME: bone marrow edema, MMT: medial meniscus tear, LMT: lateral meniscus tear, CM: chondromalacia, MFC: medial femoral condyle, MTP: medial tibial plateau, LTP: lateral tibial plateau, PF: patellofemoral, OA: osteoarthritis, FTA: femorotibial angle.

\begin{tabular}{|c|c|c|c|c|c|c|c|c|}
\hline $\begin{array}{l}\text { Patient } \\
\text { No. }\end{array}$ & $\begin{array}{l}\text { Age } \\
\text { Sex }\end{array}$ & Side & $\begin{array}{l}\text { Body } \\
\text { weight } \\
(\mathrm{Kg})\end{array}$ & $\begin{array}{l}\text { BMI } \\
(\%)\end{array}$ & $\begin{array}{l}\text { Period between } \\
\text { the onset and } \\
\text { the preop MRI }\end{array}$ & $\begin{array}{l}\text { BME or } \\
\text { osteonecrosis } \\
\text { in MRI }\end{array}$ & $\begin{array}{l}\text { Diagnosis } \\
\text { (MRI, Arthroscopy) }\end{array}$ & $\begin{array}{l}\text { OA } \\
\text { grade }\end{array}$ \\
\hline
\end{tabular}

\begin{tabular}{|c|c|c|c|c|c|c|c|c|c|}
\hline 1. & $73, \mathrm{~F}$ & $\mathrm{~L}$ & 70 & 30.3 & 12 wks & None & MMT, CM@MFC\&MTP\&PF & 2 & $175^{\circ}$ \\
\hline 2. & $64, \mathrm{M}$ & $\mathrm{R}$ & 61 & 22.4 & $10 \mathrm{wks}$ & None & MMT, CM@MFC\&MTP & 2 & $176^{\circ}$ \\
\hline 3. & $66, \mathrm{~F}$ & $\mathrm{~L}$ & 75 & 33.3 & $10 \mathrm{wks}$ & None & MMT, CM@MFC\&MTP & 2 & $182^{\circ}$ \\
\hline 4. & $74, \mathrm{~F}$ & $\mathrm{~L}$ & 50 & 22.8 & $2 \mathrm{wks}$ & None & MMT, CM@MFC\&MTP & 2 & $174^{\circ}$ \\
\hline 5. & $66, \mathrm{~F}$ & $\mathrm{R}$ & 50 & 20.3 & 4 wks & None & MMT, CM@MFC\&MTP\&LTP\&PF & 2 & $178^{\circ}$ \\
\hline 6. & $62, \mathrm{~F}$ & $\mathrm{~L}$ & 52 & 21.6 & 14 wks & None & MMT, LMT, CM@MFC\&PF & 1 & $177^{\circ}$ \\
\hline 7. & $67, \mathrm{~F}$ & $\mathrm{R}$ & 71 & 32.4 & 8 wks & None & MMT, CM@MFC\&MTP & 2 & $178^{\circ}$ \\
\hline 8. & $80, \mathrm{M}$ & $\mathrm{R}$ & 58 & 25.8 & 2 wks & None & MMT, CM@MFC\&MTP & 1 & $176^{\circ}$ \\
\hline 9. & $60, \mathrm{~F}$ & $\mathrm{R}$ & 58 & 23.2 & 32 wks & None & MMT, LMT, CM@MFC\&LTP\&PF & 2 & $168^{\circ}$ \\
\hline 10. & $63, \mathrm{~F}$ & $\mathrm{R}$ & 64 & 26.6 & $31 \mathrm{wks}$ & None & MMT, LMT, CM@MFC\&MTP & 0 & $178^{\circ}$ \\
\hline Mean & 67.5 & & 60.9 & 25.9 & 12.5 & & MMT: 10 & $\mathrm{G} 2: 7$ & 176.2 \\
\hline$(\mathrm{SD})$ & $(5.94)$ & & $(8.53)$ & $(4.43)$ & $(10.17)$ & & CM@MFC: 10 & G1: 2 & $(3.43)$ \\
\hline & & & & & & & CM@MTP: 8 & G0: 1 & \\
\hline
\end{tabular}


489 Table 2 Characteristics of the 10 patients with PAONK concerning the surgical factors. F: female, M: male, MM: medial meniscus, RT: radial tear, PH: 490 posterior horn, HT: horizontal tear, PRT: posterior root tear, PMM: partial medial meniscectomy, PLM: partial lateral meniscectomy, LMR: lateral 491 meniscus repair

\begin{tabular}{|c|c|c|c|c|c|c|}
\hline $\begin{array}{l}\text { Patient } \\
\text { No. }\end{array}$ & $\begin{array}{l}\text { Age } \\
\text { Sex }\end{array}$ & Type of MM tear & $\begin{array}{l}\text { Surgery } \\
\text { Done }\end{array}$ & $\begin{array}{l}\text { Resected } \\
\text { width of MM }\end{array}$ & $\begin{array}{l}\text { Tourniquet } \\
\text { Time }\end{array}$ & $\begin{array}{l}\text { Surgery } \\
\text { Time }\end{array}$ \\
\hline 2. & $64, \mathrm{M}$ & $\mathrm{RT}$ at $\mathrm{PH}$ & PMM & Half & $0 \mathrm{~min}$ & $35 \mathrm{~min}$ \\
\hline 3. & $66, \mathrm{~F}$ & PRT & PMM & Total & $30 \min$ & $30 \mathrm{~min}$ \\
\hline 5. & $66, \mathrm{~F}$ & PRT (with HT) & PMM & Total & $0 \mathrm{~min}$ & $25 \mathrm{~min}$ \\
\hline 6. & $62, \mathrm{~F}$ & PRT & PMM, PLM & Total & $18 \mathrm{~min}$ & $26 \mathrm{~min}$ \\
\hline 7. & $67, \mathrm{~F}$ & $\mathrm{RT}$ at $\mathrm{PH}$ & PMM & Half & $14 \min$ & $51 \mathrm{~min}$ \\
\hline 8. & $80, \mathrm{M}$ & RT at PH (with HT) & PMM & Total & $0 \mathrm{~min}$ & $25 \mathrm{~min}$ \\
\hline 9. & $60, \mathrm{~F}$ & PRT & PMM, PLM & Total & $8 \min$ & $30 \mathrm{~min}$ \\
\hline (SD) & & $5 \mathrm{RT}$ & 2 PLM 1 LMR & 2 Half & $(12.35)$ & (10.09) \\
\hline
\end{tabular}


Table 3 Clinical characteristics of the 10 patients with PAONK concerning the post-operative course and the diagnosis. PMM: partial medial 512 meniscectomy, ON: osteonecrosis, MFC: medial femoral chondyle, MTP: medial tibial plateau, BME: bone marrow edema, OA: osteoarthritis, UKA: 513 unicompartmental knee arthroplasty, TKA: total knee arthroplasty, OATS: osteochondral autograft transfer system, HTO: high tibial osteotomy

Patient Age

Residual T


Table 4 The Extrusion width (EW) and the Inner width (IW) of the medial meniscus (MM) and the lateral meniscus (LM), which were measured before meniscectomy and at the time when PAONK was diagnosed, and changes of the EW and the IW between the 2 periods, in which plus and minus values show an increase and a decrease of the width, respectively. a: comparison between the MM and the LM (unpaired t-test). b: comparison between the 2 periods (paired t-test).

\begin{tabular}{|c|c|c|c|c|c|c|c|c|c|c|c|c|c|}
\hline \multirow{3}{*}{$\begin{array}{l}\text { Patient } \\
\text { No. }\end{array}$} & \multirow{3}{*}{$\begin{array}{l}\text { Age } \\
\text { Sex }\end{array}$} & \multicolumn{4}{|c|}{ Before meniscectomy } & \multicolumn{4}{|c|}{ At the time of diagnosis of PAONK } & \multicolumn{4}{|c|}{ Changes between the 2 periods } \\
\hline & & \multicolumn{2}{|c|}{$\mathrm{EW}(\mathrm{mm})$} & \multicolumn{2}{|c|}{ IW (mm) } & \multicolumn{2}{|c|}{$\mathrm{EW}(\mathrm{mm})$} & \multicolumn{2}{|c|}{ IW (mm) } & \multicolumn{2}{|c|}{$\mathrm{EW}(\mathrm{mm})$} & \multicolumn{2}{|c|}{ IW (mm) } \\
\hline & & $\mathrm{MM}$ & LM & MM & LM & MM & LM & $\mathrm{MM}$ & LM & MM & LM & MM & LM \\
\hline 1. & $73, \mathrm{~F}$ & 7.1 & 0.0 & 2.0 & 8.0 & 8.0 & 0.0 & -1.6 & 7.9 & 0.9 & 0.0 & -3.6 & -0.1 \\
\hline 2. & $64, \mathrm{M}$ & 4.1 & -0.6 & 6.9 & 10.8 & 4.2 & -0.6 & 1.2 & 11.0 & 0.1 & 0.0 & 5.7 & 0.2 \\
\hline 3. & $66, \mathrm{~F}$ & 4.4 & 0.4 & 4.9 & 8.1 & 5.1 & 0.4 & 3.5 & 8.1 & 0.7 & 0.0 & 1.4 & 0.0 \\
\hline 4. & $74, \mathrm{~F}$ & 6.8 & -0.4 & 2.9 & 8.6 & 6.8 & -0.4 & 0.0 & 8.5 & 0.0 & 0.0 & 2.9 & -0.1 \\
\hline 5. & $66, \mathrm{~F}$ & 5.4 & -0.6 & 0.0 & 8.1 & 6.6 & -0.6 & -1.2 & 8.5 & 1.2 & 0.0 & 1.2 & 0.4 \\
\hline 6. & $62, \mathrm{~F}$ & 3.5 & 1.3 & 6.1 & 7.2 & 6.1 & 1.3 & 1.4 & 7.0 & 2.6 & 0.0 & 4.7 & 0.2 \\
\hline 7. & $67, \mathrm{~F}$ & 5.8 & 0.0 & 1.7 & 7.2 & 6.1 & 0.0 & -2.1 & 7.8 & 0.3 & 0.0 & 3.8 & 0.6 \\
\hline 8. & $80, \mathrm{M}$ & 3.7 & -1.1 & 6.5 & 12.7 & 5.9 & -1.3 & 0.6 & 13.3 & 2.2 & -0.2 & 5.9 & 0.6 \\
\hline 9. & $60, \mathrm{~F}$ & 2.8 & -1.8 & 6.1 & 10.6 & 4.8 & -1.8 & 1.6 & 7.9 & 2.0 & 0.0 & 4.5 & -2.7 \\
\hline 10. & $63, \mathrm{~F}$ & 3.4 & 0.6 & 7.1 & 9.4 & 4.9 & 0.8 & 2.2 & 9.0 & 1.5 & 0.2 & 4.9 & -0.4 \\
\hline $\begin{array}{l}\text { Mean } \\
(\mathrm{SD})\end{array}$ & & $\begin{array}{l}4.7 \\
(1.4)\end{array}$ & $\begin{array}{l}-0.2 \\
(0.8)\end{array}$ & $\begin{array}{l}4.4 \\
(2.4)\end{array}$ & $\begin{array}{l}9.1 \\
(1.7)\end{array}$ & $\begin{array}{l}5.9 \\
(1.1)\end{array}$ & $\begin{array}{l}-0.2 \\
(0.9)\end{array}$ & $\begin{array}{l}0.6 \\
(1.7)\end{array}$ & $\begin{array}{l}8.9 \\
(1.8)\end{array}$ & $\begin{array}{l}1.2 \\
(0.9)\end{array}$ & $\begin{array}{l}0.0 \\
(0.1)\end{array}$ & $\begin{array}{l}3.9 \\
(1.5)\end{array}$ & $\begin{array}{l}-0.2 \\
(0.9)\end{array}$ \\
\hline$P$ value & & $\mathrm{P}<0$ & & $\mathrm{P}<$ & $01^{\mathrm{a}}$ & & $01^{\mathrm{a}}$ & & $01^{\mathrm{a}}$ & $\mathrm{P}=0.0031^{\mathrm{b}}$ & N.S. ${ }^{b}$ & $\mathrm{P}<0.0001^{\mathrm{b}}$ & N.S. ${ }^{b}$ \\
\hline
\end{tabular}




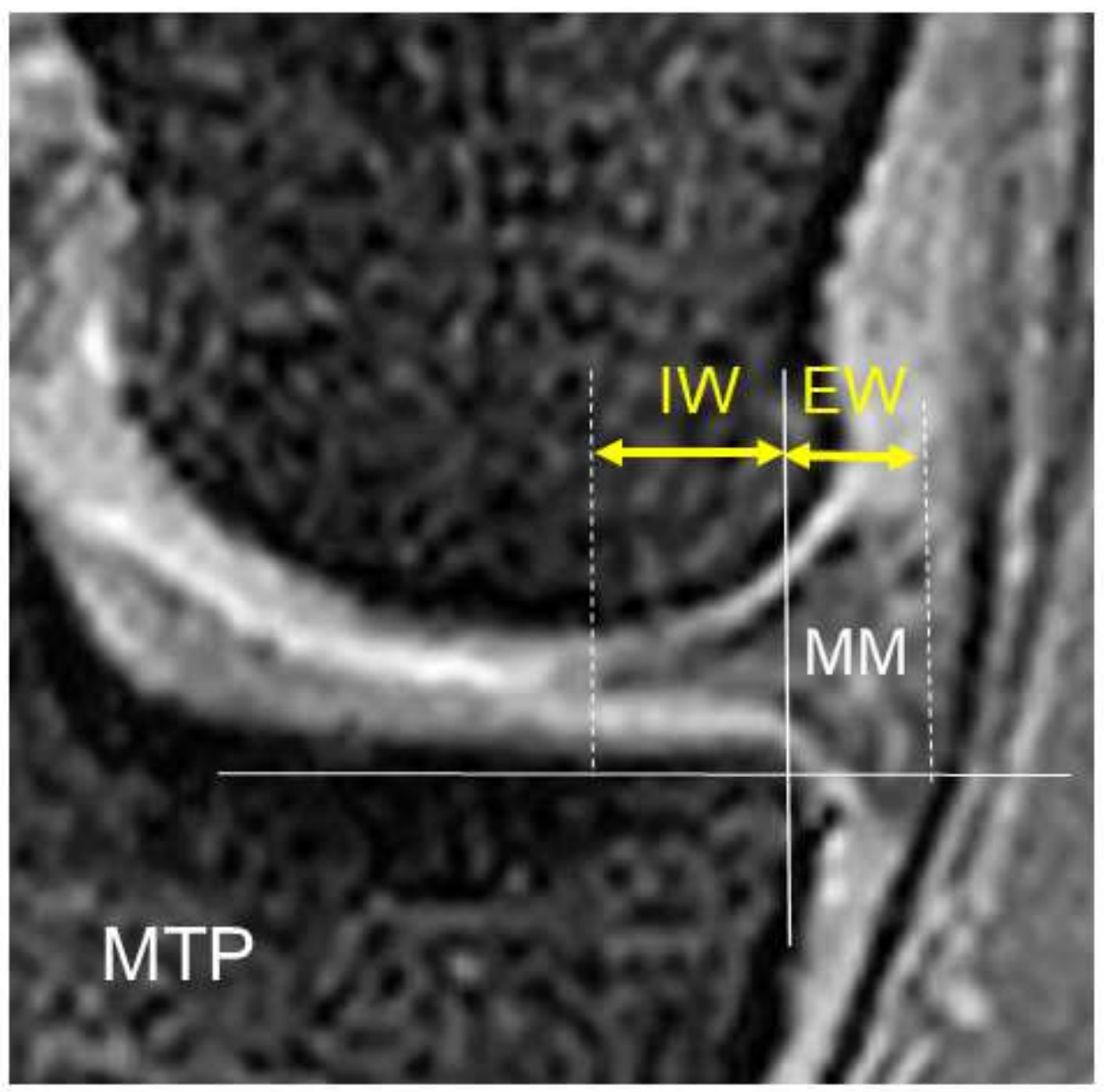

\section{Figure 1}

Measurement of the location of the medial meniscus (MM) on the coronal image of the MRI. A vertical line intersecting the peripheral margin of the medial tibial plateau (MTP) was drawn. Then, the second and third lines, which were parallel to the first line, were drawn at the outer and inner margins of the meniscus, respectively. We measured the distance between the first and second lines, which was defined as "Extrusion width (EW)", and the distance between the first and third lines, which was defined as "Inner width (IW)". Each width was quantified in millimeters. 


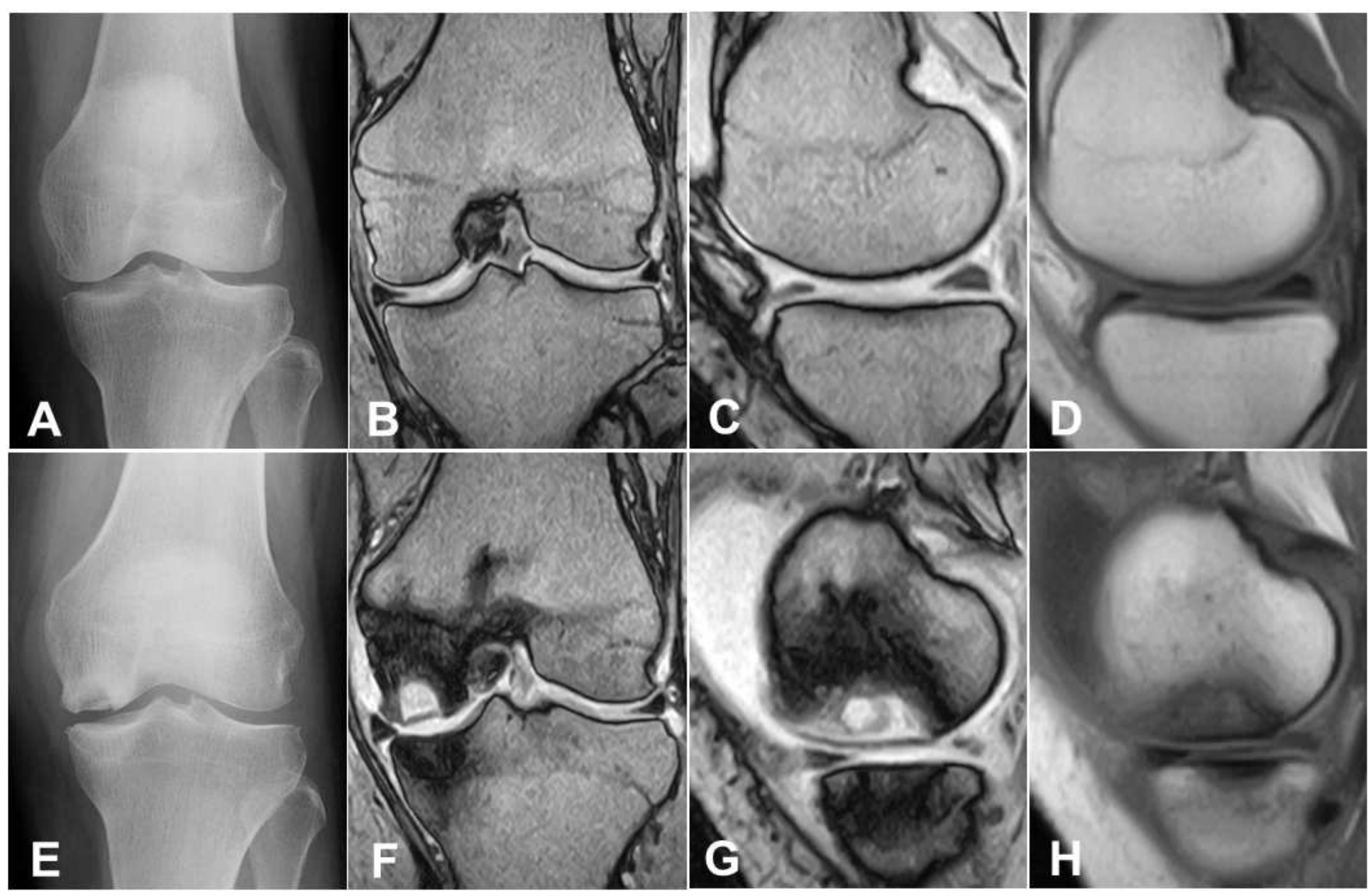

Figure 2

62-year old woman. Preoperatively, the radiogram (A) showed grade-1 OA. The MR images (B and C: T2*, D: T1) did not show any findings of osteonecrosis or bone marrow edema (BME). The Inner width (IW) and the Extrusion width (EW) of the MM were $6.1 \mathrm{~mm}$ and $3.5 \mathrm{~mm}$, respectively (B). At 3 months postoperatively, the radiograms (E) indicated stage-3 osteonecrosis in the medial femoral condyle (MFC). MR images (F and G: T2*, H: T1) showed a necrotic lesion (T1-low, T2*-high) in the MFC, which was surrounded by an osteosclerotic zone and a wide BME area. The IW decreased to $1.4 \mathrm{~mm}$, and the EW increased to $6.1 \mathrm{~mm}(\mathrm{~F})$. 


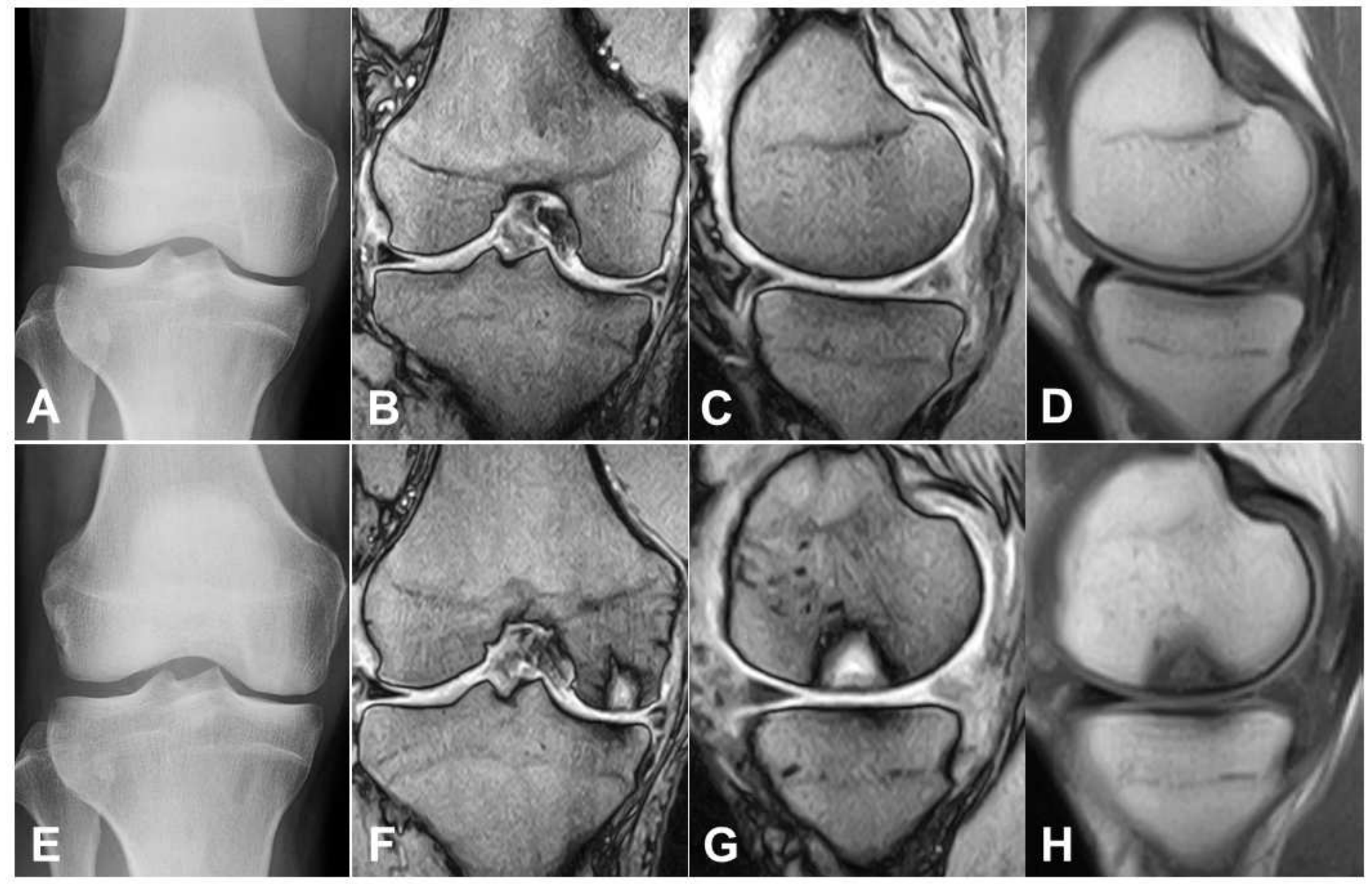

\section{Figure 3}

64-year old man. Preoperatively, the radiogram (A) showed grade-2 OA. The MR images (B and C: T2*, D: T1) did not show any findings of osteonecrosis or bone marrow edema (BME). The Inner width (IW) and the Extrusion width (EW) of the MM were $6.9 \mathrm{~mm}$ and $4.1 \mathrm{~mm}$, respectively (B). At 4 months postoperatively, the radiograms (E) indicated stage-2 osteonecrosis in the medial femoral condyle (MFC). MR images ( $F$ and G: T2*, H: T1) showed a necrotic lesion (T1-low, T2*-high) in the MFC, which was surrounded by an osteosclerotic zone. The IW decreased to $1.2 \mathrm{~mm}$, while the EW was $4.2 \mathrm{~mm}$ (F). 


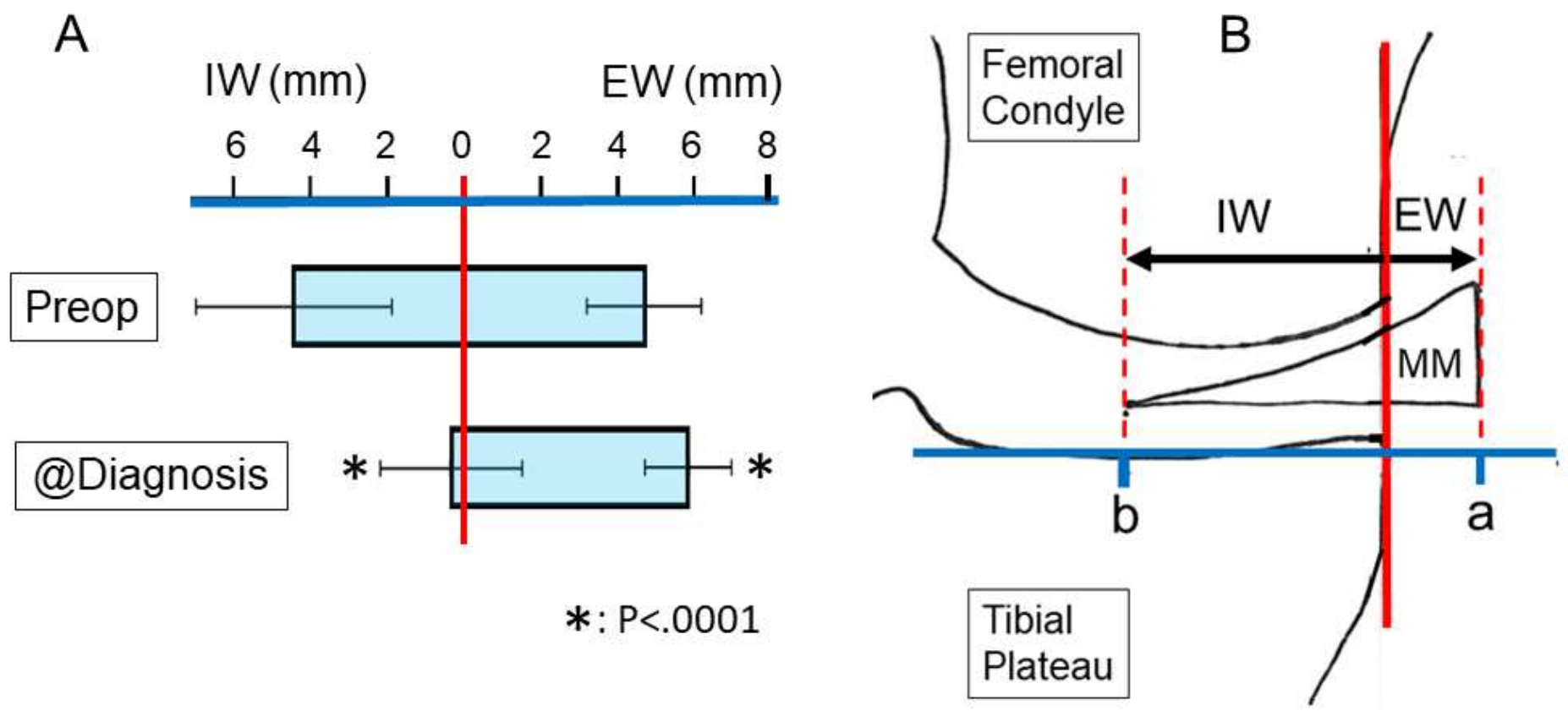

Figure 4

A: Comparison of the medial meniscus (MM) locations measured before the meniscectomy (Preop) and at the time of diagnosis of PAONK (@Diagnosis). The Extrusion width (EW) and the Inner width (IW), the definition of which is shown in a schematic picture $(B)$, were significantly $(P<0.0001)$ changed between the 2 periods. This bar graph also shows that the disappearance of the IW of the MM was caused by not only the decrease of the total meniscal width due to meniscectomy but also the meniscal extrusion. 